\title{
Segmentasi Citra Medis untuk Deteksi Objek FAM pada Payudara Menggunakan Metode Sobel
}

\author{
Riska Nanda*, Sri Wulan Dari, Ahmad Ihsan \\ Fakultas Teknik, Program Studi Teknik Informatika, Universitas Samudra, Langsa, Indonesia \\ Email: 1"riskananda5@gmail.com,wulandaryal23@gmail.com, ahmadihsan@unsam.ac.id
}

\begin{abstract}
Abstrak
Fibroa Adenoma Mammae (FAM) atau disebut tumor jinak merupakan tumor yang paling umum ditemukan pada payudara, seringkali penyakit ini dianggap sebagai kanker payudara oleh sebagian kaum awam namun penyakit ini berbeda dengan kanker karena Fibroadenoma (FAM) dapat tumbuh di seluruh bagian payudara, Dalam mengidentifikasi FAM, biasanya dokter atau radiologis harus menganalisa dengan cermat image hasil Resonansi Magnetik yang disimpan dalam format Digital Imaging Communication In Medicine (DICOM) proses ini tentunya cukup memakan waktu. Dengan demikian penulis merasa perlu untuk membuat sebuah aplikasi pengolahan citra digital untuk membantu pihak dokter atau radiologi mengidentifikasi FAM pada payudara dengan memanfaatkan proses segmentasi pada citra medis hasil USG menggunakan metode Sobel. Metode ini melakukan proses segmentasi citra asli dengan mendeteksi garis tepi pada gambar kemudian hasil segmentasi di konversi kedalam citra biner agar sistem dapat menentukan area FAM. Segmentasi citra medis dengan metode Sobel baik dilakukan untuk menentukan tepi pada objek FAM karena batas tepi dapat terlihat jelas namun untuk sebagian citra gambar dengan resolusi kurang seperti yang telah dilakukan uji coba sebelumnya deteksi tepi ini akan sulit menentukan tepi pada objek yang halus dan hanya membentuk garis tepi yang kasar.
\end{abstract}

Kata Kunci: Fibroa Adenoma Mammae, Segmentasi, Deteksi objek, Citra digital, Sobel

\begin{abstract}
Fibroa Adenoma Mammae (FAM) or called a benign tumor is the most common tumor found in the breast, often this disease is considered as breast cancer by some laymen, but this disease is different from cancer because Fibroadenoma (FAM) can grow in all parts of the breast, In identifying FAM, doctors or radiologists usually have to analyze carefully the images of Magnetic Resonance stored in the format of Digital Imaging Communication In Medicine (DICOM). This process is certainly quite time consuming. Thus the author feels the need to create a digital image processing application to help doctors or radiologists identify FAM in the breast by utilizing the segmentation process in medical images of USG results using the Sobel method. This method performs the original image segmentation process by detecting the edges of the image then the segmentation results are converted into binary images so the system can determine the FAM area. Medical image segmentation using the Sobel method is good for determining the edges of FAM objects because the edges can be clearly seen but for some image images with less resolution as previously tested, edge detection will be difficult to determine the edges of smooth objects and only form lines rough edges.
\end{abstract}

Keywords: Fibroa Adenoma Mammae, Segmentation, Object Detection, digital Image, Sobel

\section{PENDAHULUAN}

Fibroadenoma (FAM) atau disebut tumor jinak merupakan tumor yang paling umum ditemukan pada payudara. Berdasarkan penelitian di Yaman mulai Januari 2006 - Desember 2009 ditemukan sebanyak 635 kasus yang didiagnosis sebagai penyakit tumor payudara. Terdapat kelainan sebanyak 493(77.6\%) yang merupakan penyakit tumor jinak payudara pada usia kurang dari 30 tahun, dan 142 (22.4\%) penyakit tumor payudara ganas pada rentang usia 40-49 tahun. Dari seluruh kejadian tumor jinak payudara, yang paling sering terjadi adalah FAM 40,5\% dengan rentang usia 20-29 tahun. Fam adalah lesi yang paling banyak dan umum terjadi dengan 318 kasus (44\%) yang terjadi pada usia rata-rata 16-32 tahun [1].

Seringkali penyakit ini dianggap sebagai kanker payudara oleh sebagian kaum awam namun penyakit ini berbeda dengan kanker karena fibroadenoma (FAM) dapat tumbuh di seluruh bagian payudara, namun umumnya pada kuadran atas lateral. Fibroadenoma teraba sebagai benjolan bulat dengan konsistensi padat. Tumor ini tidak melekat pada jaringan sekitarnya dan amat mudah digerakkan. Fibroadenoma paling sering terdeteksi secara kebetulan selama pemeriksaan medis atau selama pemeriksaan sendiri. Dalam mengidentifikasi tumor payudara, pihak dokter atau radiologis menganalisa image hasil Resonansi Magnetik yang disimpan dalam format .dcom Digital Imaging Communication In Medicine (DICOM).

Keahlian sangatlah penting serta mempengaruhi tim medis agar diagnosa yang diberikan tepat dan akurat, sehingga penanganannya pun dapat dilakukan dengan tepat. Oleh karena demikian, penulis merasa perlu untuk membuat sebuah aplikasi pengolahan citra digital dengan memanfaatkan proses segmentasi dan deteksi tepi objek untuk membantu dokter atau radiologis dalam mengidentifikasi tumor jinak atau sering disebut FAM payudara.Penggunaan pengolahan citra digital telah banyak diimanfaatkan dalam dunia pendidikan maupun kesehatan salah satunya digunakan dalam proses segmentasi citra, pengolahan citra digital (Digital Image Processing) adalah sebuah disiplin ilmu yang mempelajari tentang teknik-teknik mengolah citra [2]. Segmentasi citra ditujukan untuk mendapatkan objek-objek yang terkandung didalam citra dan memisahkannya dari latar belakangnya, sedangkan deteksi tepi dilakukan untuk memperoleh tepi-tepi objek Dalam hal ini citra medis diidentifikasi menggunakan deteksi tepi orde pertama yaitu metode sobel [3]. 
Sebelumnya, penelitian untuk mengidentifikasi telah berhasil dilakukan oleh Fitri Suryaningsih [4], dengan memanfaatkan deteksi tepi menggunakan metode canny dan membandingkan nya dengan metode lainnya. penelitian yang sama juga dilakukan oleh Fakhrurrozi dkk, yang memanfaatkan segmentasi citra untuk mengidentifikasi objek tumor menggunakan metode active contour yang mampu melakukan segmentasi citra pada objek multi region dan objek yang saling berdekatan namun sensitif terhadap derau, sedangkan penelitian untuk mengidentifikasi tumor jinak pada payudara menggunakan citra medis hasil USG masih jarang ditemukan Oleh karena itu, penulis mencoba meneliti pemrosesan citra medis hasil USG dengan menggunakan metode sobel untuk membantu dokter atau radiologis dalam mengidentifikasi tumor payudara [5].

Aplikasi segmentasi citra medis menggunakan metode sobel ini dibangun menggunakan Aplikasi Matlab, yang diharapkan nantinya aplikasi ini dapat mempermudah kinerja tim medis terkhusus pada bagian radiologi.

\section{METODE PENELITIAN}

\subsection{Fibroa Adenoma Mammae (FAM)}

Fibroadenoma merupakan tumor jinak yang dapat tumbuh di seluruh bagian payudara, namun tersering pada kuadran atas lateral. Fibroadenoma teraba sebagai benjolan bulat dengan konsistensi padat. Tumor ini tidak melekat pada jaringan sekitarnya dan amat mudah digerakkan. Fibroadenoma paling sering terdeteksi secara kebetulan selama pemeriksaan medis atau selama pemeriksaan sendiri. Fibroadenoma raksasa biasanya ditemui pada perempuan hamil atau menyusui. Fibroadenoma dapat tumbuh multipel.

Fibroadenoma memiliki gejala berupa benjolan dengan permukaan yang licin dan merah. Biasanya fibroadenoma tidak nyeri, tetapi kadang dirasakan nyeri bila ditekan. Secara morfologi, fibroadenoma ditemukan sebagai nodul diskret, biasanya soliter, dapat digerakkan secara bebas, dan berukuran 1-10cm. Durasi gejala bervariasi dari satu bulan sampai enam tahun, mungkin karena pertumbuhan tumor yang lambat dan tidak menimbulkan rasa sakit. Fibroadenoma pada sebagian besar penderita tidak menunjukkan gejala dan terdeteksi setelah dilakukan pemeriksaan fisik. Pertumbuhan fibroadenoma relatif lambat dan hanya menunjukkan sedikit perubahan ukuran dan tekstur dalam beberapa bulan [6].

\subsection{Citra Digital}

Citra Digital merupakan representasi dari fungsi intensitas cahaya dalam bidang dua dimensi. Berdasarkan jenis warnanya, citra dapat dikelompokkan menjadi tiga jenis yaitu citra RGB, citra grayscale, dan citra biner [7]. Pengolahan citra digital (Digital Image Processing) adalah sebuah disiplin ilmu yang mempelajari tentang teknikteknik mengolah citra. Citra yang dimaksud disini adalah gambar diam (foto) maupun gambar bergerak (yang berasal dari webcam). Sedangkan digital disini mempunyai maksud bahwa pengolahan citra/gambar dilakukan secara digital menggunakan computer.

Sebuah citra digital dapat diwakili oleh sebuah matriks dua dimensi $\mathrm{f}(\mathrm{x}, \mathrm{y})$ yang terdiri dari $\mathrm{M}$ kolom dan $\mathrm{N}$ baris, dimana perpotongan antara kolom dan baris disebut piksel (pixel = picture element) atau elemen terkecil dari sebuah citra.

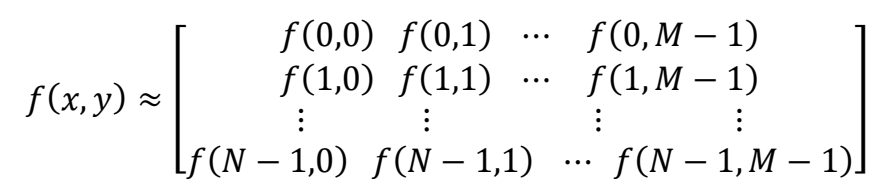

Suatu citra $f(x, y)$ dalam fungsi matematika dituliskan sebagai berikut:

$$
\begin{gathered}
0 \leq x \leq M-1 \\
0 \leq y \leq N-1 \\
0 \leq f(x, y) \leq G-1
\end{gathered}
$$

Dimana:

$\mathrm{M}=$ jumlah piksel baris (row) pada array citra

$\mathrm{N}=$ jumlah piksel kolom (column) pada array citra

$\mathrm{G}=$ nilai skala keabuan (graylevel)

Besarnya nilai M, N dan G pada umumnya merupakan perpangkatan dari dua.

$$
M=2^{\mathrm{m}}: \mathrm{N}=2^{\mathrm{n}} ; \mathrm{G}=2^{\mathrm{k}}
$$

Dimana nilai $\mathrm{m}, \mathrm{n}$ dan $\mathrm{k}$ adalah bilangan bulat positif. Interval $(0, \mathrm{G})$ disebut skala keabuan (grayscale). Besar $\mathrm{G}$ tergantung pada proses digitalisasinya. Biasanya keabuan 0 (nol) menyatakan intensitas hitam dan 1 (satu) menyatakan intensitas putih. Untuk citra 8 bit, nilai G sama dengan $2_{8}=256$ warna (derajat keabuan). 


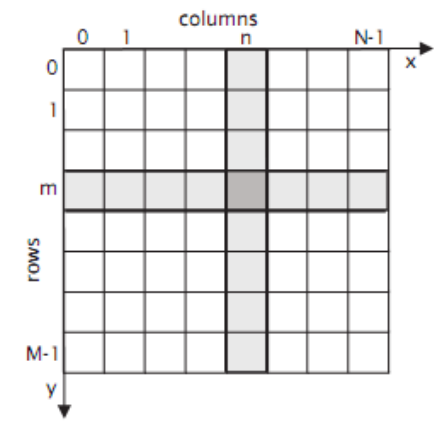

Gambar 1. Representasi citra digital dalam dua dimensi [2].

\subsection{Deteksi Tepi}

Deteksi tepi berfungsi untuk memperoleh tepi objek. Deteksi tepi memanfaatkan perubahan nilai intensitas yang drastis pada batas dua area. Definisi tepi di sini adalah "himpunan piksel yang terhubung yang terletak pada batas dua area". Perlu diketahui, tepi sesungguhnya mengandung informasi yang sangat penting. Informasi yang diperoleh dapat berupa bentuk maupun ukuran objek. Umumnya, deteksi tepi menggunakan dua macam detektor, yaitu detektor baris (Hy) dan detektor kolom (Hx). Beberapa contoh yang tergolong jenis ini adalah operator Roberts, Prewitt, Sobel, dan Frei-Chen. Deteksi tepi dapat dibagi menjadi dua golongan. Golongan pertama disebut deteksi tepi orde pertama, yang bekerja dengan menggunakan turunan atau diferensial orde pertama. Termasuk kelompok ini adalah operator Roberts, Prewitt, dan Sobel. Golongan kedua dinamakan deteksi tepi orde kedua, yang menggunakan turunan orde kedua. Contoh yang termasuk kelompok ini adalah Laplacian of Gaussian (LoG) [3].

\subsection{Metode Sobel}

Operator sobel adalah salah satu operator yang menghidari adanya interpolasi. Operator ini lebih sensitive terhadap tepian diagonal dari pada tepian vertikal dan horizontal. Operator sobel menggunakan kernel berukuran 3x3 piksel.

\section{ANALISA DAN PEMBAHASAN}

Penelitian ini menggunakan Matlab 7.8.0 (R2009a) sebagai software. Sedangkan input yang digunakan yaitu citra FAM hasil USG. Agar dapat memahami langkah kerja dari aplikasi yang akan dirancang maka dapat dilihat pada flowchart pada gambar 2:

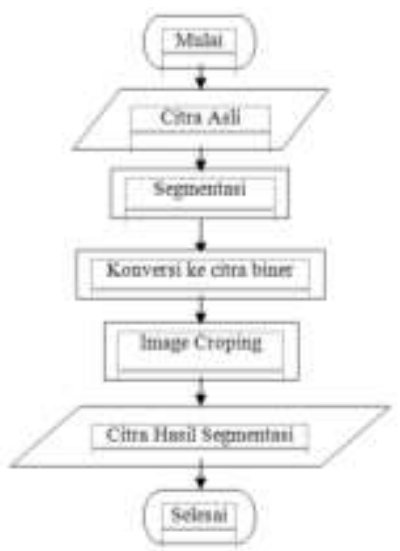

Gambar 2. Diagram Alir Sistem

Penjelasan dari diagram alir sebagai berikut:

1. Sample Citra FAM yang diambil berupa data citra hasil USG dengan format .dcom

2. Proses segmentasi dilakukan menggunakan metode sobel.

3. Citra hasil segmentasi kemudian di konversi kedalam bentuk citra biner agar mempermudah sistem mengenali area yang merupakan tumor FAM.

4. Area yang telah dideteksi sebagai daerah tumor kemudian di crop.

Pada proses segmentasi data yang digunakan adalah citra medis digital yaitu hasil USG payudara abnormal, citra dari 2 orang pasien di segmentasi menggunakan metode sobel, kemudian hasil dari masing-masing operasi ditampilkan dengan menggunakan Matlab 7.8.0 (R2009a) sebagai perangkat lunak. Agar lebih memahami proses segmentasi citra tumor FAM maka proses segmentasi dilakukan sesuai dengan urutan nomor yang sesuai pada interface yang dapat dilihat pada gambar 3. 


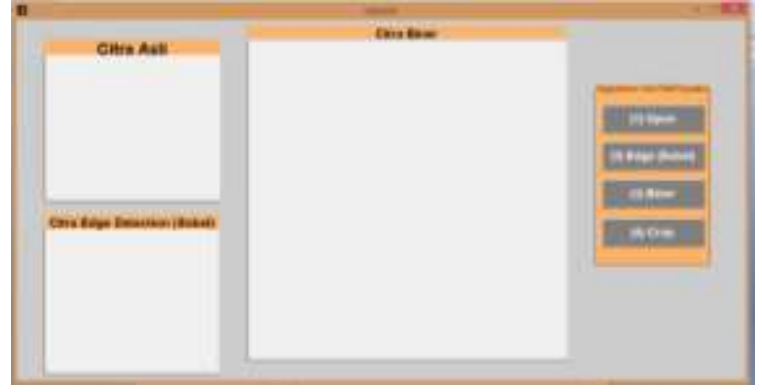

Gambar 3. Tampilan Interface Program

Tombol open berfungsi untuk membuka direktori penyimpanan dan memasukkan citra asli yang akan disegmentasi selain itu program hanya dapat menampilkan citra dengan format yang sesuai. Tampilan gambar citra asli dapat dilihat pada gambar 4.

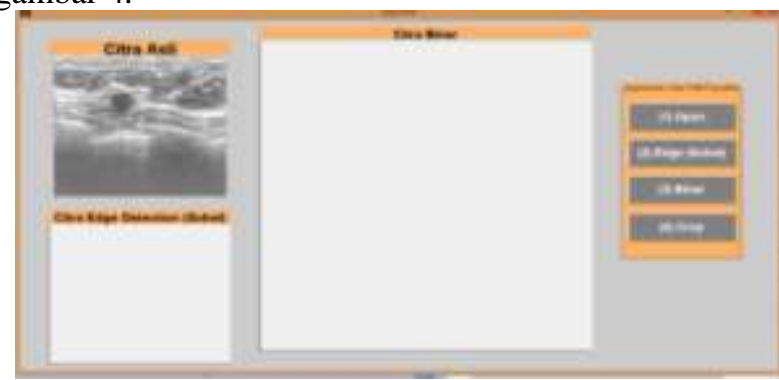

Gambar 4. Interface hasil input citra asli

Selanjutnya dilakukan proses segmentasi citra menggunakan metode sobel dimana metode ini mendeteksi tepi dari citra asli seperti terlihat pada gambar 5.jika gambar berhasil di segmentasi citra diubah kedalam bentuk biner proses ini dilakukan untuk memperjelas area FAM sehingga dapat memudahkan program dalam proses image cropping.

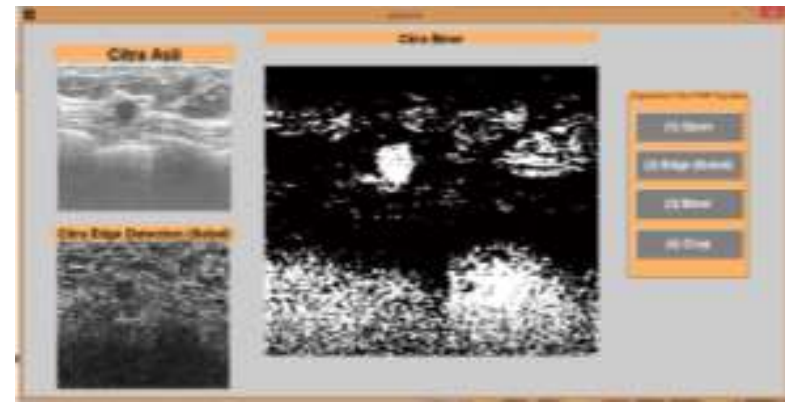

Gambar 5. Interface hasil deteksi tepi metode sobel

Tombol crop berfungsi untuk menampilkan area FAM hasil segmentasi yang telah di crop. Dilakukannya proses cropping bertujuan agar pengguna dapat lebih mudah mudah dan lebih fokus ke area yang merupakan penyakit FAM tersebut. Hasil crop dapat dilihat pada gambar 7 .

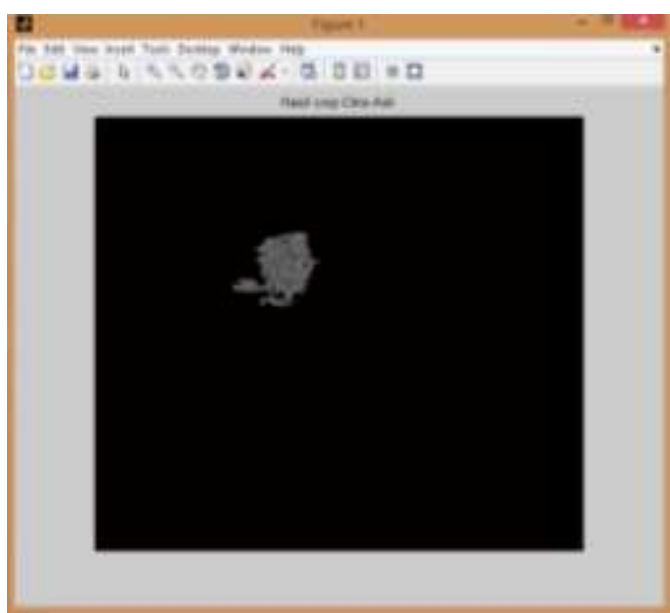

Gambar 6. Interface hasil image cropping 


\section{IMPLEMENTASI}

Implementasi dilakukan dengan meng-input-kan file citra digital hasil USG kedalam program yang telah dibuat, selain itu pada tahap ini juga akan dilakukan pengujian terhadap proses deteksi tepi. Pengujian dilakukan berdasarkan kualitas edge yang dihasilkan. Adapun sample citra yang akan diuji yang tertera pada gambar 8 merupakan dua citra jenis .dkom dengan size dan dimensions yang berbeda. Citra ke-1 adalah citra dengan dimensions 493x438 dengan size $639 \mathrm{~kb}$. sedangkan citra ke-2 memiliki dimensions 266x203 dan size $158 \mathrm{~kb}$.

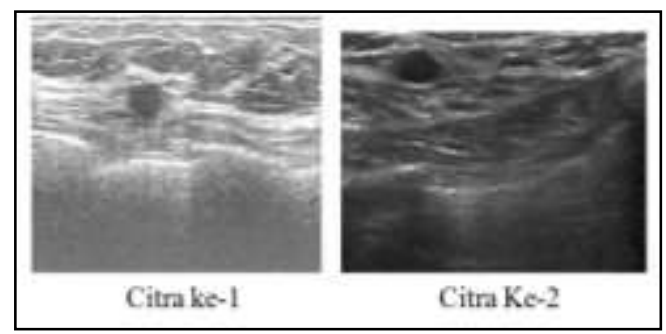

Gambar 7. Input Citra mammae abnormal

\subsection{Pengujian Segmentasi Citra}

Proses deteksi tepi dengan menggunakan metode sobel dari kedua sample menghasilkan citra dengan penampakan garis batas berbeda tiap-tiap daerah atau obyek dimana citra ke-1 garis tepinya terlihat jelas dan tidak terdapat tepi yang terputus dibandingkan citra kedua dimana garisnya tidak terlihat jelas. Adapun hasil pengujian deteksi tepi terhadap beberapa citra hasil segmentasi dapat dilihat pada gambar 9.

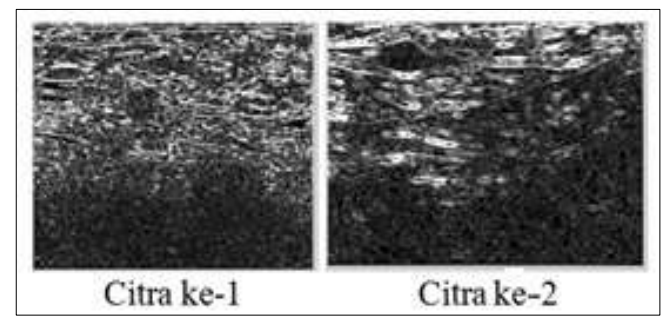

Gambar 8. Citra hasil segmentasi

\subsection{Pengujian Konversi Ke Nilai Biner}

Proses Konversi ke bentuk nilai biner dilakukan setelah proses deteksi tepi dengan menggunakan metode Sobel. Dari hasil pengujian terlihat hasil biner sesuai dengan hasil deteksi tepi, dan nilai biner dari tepi dan obyek citra ditandai dengan angka 1 untuk setiap tepi obyek dan angka 0 untuk obyek selain tepi. Hal ini sangat membantu, terutama dalam mengidentifikasi tepi citra abnormal yang dicurigai sebagai FAM. Hasil pengujian konversi ke nilai biner untuk kedua citra abnormal ditunjukkan pada gambar dibawah ini:

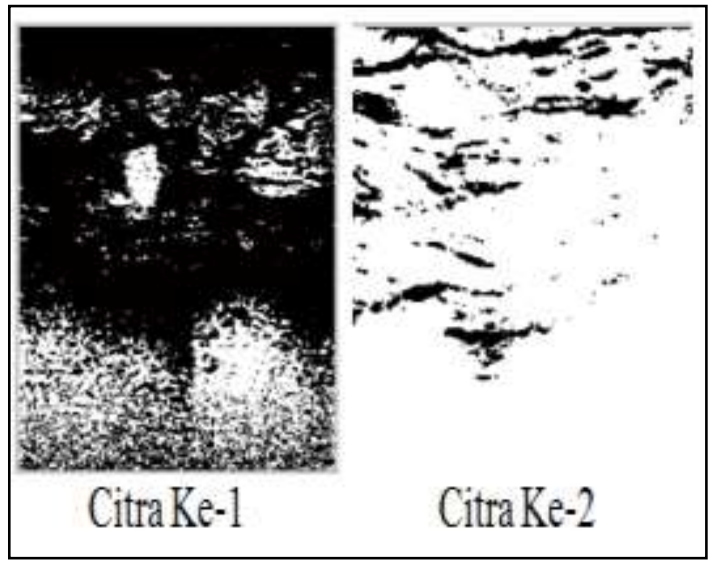

Gambar 10. Citra hasil binerisasi

Hasil biner pada kedua citra yang tertera pada gambar 10 dapat dianalisis bahwa pada citra ke-2 garis tepi sudah tidak terlihat jelas. Hal ini dapat disebabkan karena dimensions dan size yang terlalu rendah sehingga kualitas citra menjadi menurun. 


\subsection{Hasil Crop}

Hasil crop yang terlihat pada gambar 11, citra Ke-1 menampilkan area yang ditandai sebagai objek FAM sedangkan pada citra ke-2 program tidak dapat mendeteksi area tersebut dikarenakan citra ke-2 beresolusi rendah sehingga program hanya menampilkan seluruh area kosong pada interface crop.

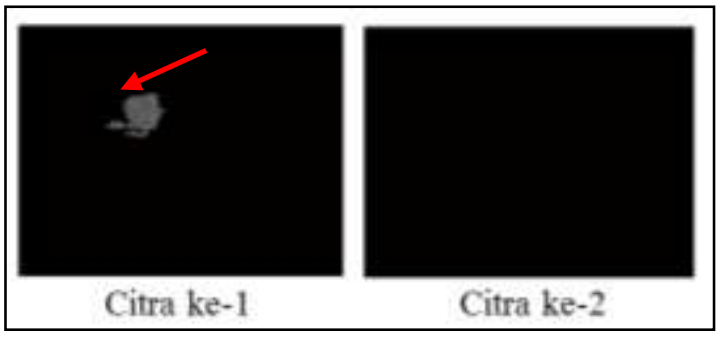

Gambar 11. Citra hasil crop

\section{KESIMPULAN}

Berdasarkan dari pembahasan dalam penelitian yang telah dilakukan, dapat disimpulkan bahwa proses Segmentasi citra medis dengan metode sobel baik dilakukan untuk menentukan tepi pada objek FAM karena batas tepi dapat terlihat jelas namun untuk sebagian citra gambar dengan resolusi kurang seperti yang telah dilakukan uji coba sebelumnya deteksi tepi ini akan sulit menentukan tepi pada objek yang halus dan hanya membentuk garis tepi yang kasar sehingga objek tidak dapat terdeteksi dengan baik.

\section{REFERENCES}

[1] M. Fam, P. Pasien, W. Yang, and B. Di, "Faktor-Faktor Yang Menyebabkan Kejadian Fibroadenoma Poliklinik Spesialis Bedah Umum," vol. 2, no. 23, pp. 1-10, 2018.

[2] R. D. Kusumanto and A. N. Tompunu, "Pengolahan Citra Digital Untuk Mendeteksi Obyek Menggunakan Pengolahan Warna Model Normalisasi Rgb," vol. 2011, no. Semantik, 2011.

[3] E. Farijki and B. K. Triwijoyo, "Segmentasi Citra Mri Menggunakan Deteksi Tepi,” Tek. Staf pengajar jurusan Bumigora, Inform., pp. $17-24,1858$.

[4] F. Fitri “Algoritma Deteksi Tepi (Edge Detection) Untuksegmentasi Citra Tumor Hepar” vol. 06, No. 01, Juni 2012.

[5] F. Basyid, K. Adi, F. Sains, and U. Diponegoro, "Segmentasi Citra Medis Untuk Pengenalan Objek Kanker Menggunakan Metode Active Contour," vol. 3, no. 3, pp. 209-216, 2014.

[6] C. E. Boom et al., "Infark Miokard Perioperatif Diagnosis dan Penata laksanaan Fibroadenoma Payudara," vol. 20, no. 53, pp. 37-45, 2014

[7] A. S. Hyperastuty and R. Riries, "Artificial Neural Network Dalam Menentukan Grading Histopatologi Kanker Payudara," vol. 19, no. $2,2017$. 